\title{
Awareness, Prevalence and Determinants of Birth Control Methods Use among Women in Saudi Arabia
}

\author{
Rehab Mohamed Elgharabawy', Amira Saber Ahmed ${ }^{2}$, \\ Ray Abdulla Alsuhaibani ${ }^{3}$
}

\section{Abstract}

Objectives: The aim of this study was to characterize Saudi women's current contraceptive choices and adherence to contraceptive regimens and to determine the knowledge, attitude and practice of contraception and the associated socio-demographic factors among a representative sample of Saudi married women in Al-Qassim region, KSA.

Methodology: Cross-sectional survey of women in Saudi Arabia aged 18-49 years $(n=300)$ was conducted. Questions include knowledge and attitude towards contraception, history of pregnancy, cause for use and reasons for avoiding contraception.

Results: Of the 287 survey participants, 40 (13.9\%) women were not used contraception. Among the 247 women who used contraception, the most frequently used current methods were oral contraceptive (49.1\%) condom (17.1\%) and intrauterine device (16\%). There was a significant increase in contraceptive used among working women, 30 years and older, with high level of education, and those having a large number of children.

Conclusion: there is deficient in the awareness of contraceptive methods in Al-Qassim region, Saudi Arabia as well as the knowledge, attitude, and practice of family planning.
1 Pharmacology and Toxicology Department, Faculty of Pharmacy, Tanta University, Egypt.

2 Hormone Department, National Research Centre, Egypt.

3 College of Pharmacy, Qassim University, Saudi Arabia.

Contact information:

Rehab Mohamed Elgharabawy.

Address: Pharmacology and Toxicology Department, college of Pharmacy, Qassim University, Saudi Arabia.

Tel: 00966562071661.

झdrrehab200932@yahoo.com

\section{Keywords}

Awareness; birth control methods; prevalence; Al-Qassim region.

\section{Introduction}

The use of contraceptive methods has become an essential factor in the life of the most reproductive age group of women, although it varies at different points of their life course. In order to promote 
women's reproductive health and prevent the risk of unwanted pregnancies, the use of effective contraceptive methods is paramount important. [1]

Every year, approximately 350,000 women die while pregnant or giving birth. Of these women, 99\% die in developing countries. An estimated 8 million more women suffer serious illnesses and lifelong disability as a result of complication during childbirth. [1]

There is a paucity of data regarding contraceptive use in Saudi Arabia, and data from studies conducted abroad cannot reflect the tendencies in the Saudi population. Some women do not use oral contraceptive pills (OCPs) because of their incorrect perceptions regarding their utilization. [2] Secondly, the medications that are used for emergency contraception are available through Gynecologist prescription in Saudi Arabia. [3]

In Saudi Arabia, OCPs are available over-the-counter without prescription, and a pharmacist's advice might sometimes be a user's only source of information. $[4,5]$ Self-medication may result in inappropriate use of pills and consequently poor efficacy. However, women tend to start contraception on their own because of high fertility rates, less accessibility to health care for women, and large families. In one report, [6] it was found that $28.7 \%$ of Saudi women used an OCP for contraception. Most of the women lacked knowledge about OCPs and had a negative attitude toward their use. Although over three quarters of the women had some knowledge about what to do if they missed a pill, less than $10 \%$ knew exactly what to do. Thus, in Saudi Arabia there are gaps in the knowledge and practices of women using OCPs for birth control. If large gaps in knowledge about OCP use are identified among users, recommendations can be made for health care providers to provide contraceptive counseling to all women.

Studies conducted in Saudi Arabia showed low levels of use of contraceptives with only (27\%) of women in Abha and (44\%) of women in Qassim region. The national data of the Kingdom shows $(31.8 \%)$ contraceptive use rate in 1996 . This percentage has fallen down in 2007 to be (23.8\%). [7] In contrast, a study that was conducted in AlKhobar showed high use of contraceptives among the Saudi Arabian females with (74.8\%). [8] It is well documented that effective family planning programs can minimize unintended pregnancies, reduce maternal mortality, and improve child survival. [9]

Research may be used to explore patients' knowledge, attitudes and information requirements; one method of doing this is through the use of focus groups [10]. Results can be utilized to provide patients with the quality evidence they require in a format that they find acceptable. The provision of information to patients enhances patient choice. [11]

Among women who use reversible contraception, most choose less-effective methods such as condoms (26\%) and oral contraceptive pills (45\%) [11]. Recently published data from the National Survey of Family Growth show an increase in the use of long-acting reversible contraceptives (LARC) that include intrauterine devices (IUDs) and implants. [12, 13] LARC are not only the most effective methods, but also appear to provide the highest satisfaction and rate of continuation among users. [14]

Contraceptive choice is in part dependent on the effectiveness of the contraceptive method in preventing unplanned pregnancy, which, in turn, is dependent for some methods not only on the protection afforded by the method itself, but also on how consistently and correctly it is used. Both consistent and correct use can vary greatly with such characteristics as age, income, users' desire to prevent or delay pregnancy, and culture. Methods that depend on consistent and correct use by clients have a wide range of effectiveness. Most men and women tend to be more effective users as they become more experienced with a method. However, programmatic aspects also have a profound effect 
on how effectively the method will be used. [15] This study in Qassim region would help to understand the scenario of contraception use.

\section{Aim of the work}

The aim of this study was to characterize Saudi women's current contraceptive choices and adherence to contraceptive regimens and to determine the knowledge, attitude and practice of contraception and the associated socio-demographic factors among a representative sample of Saudi married women in Al Qassim region, KSA.

\section{Subjects and methods}

\section{Study design}

A national cross-sectional survey was conducted on Saudi married women aged 18-49 years old who had not reached menopause in March-April 2015. A standardized, confidential, Internet questionnaire was administered to female members.

\section{Questionnaire}

The questionnaire was designed in English and later translated to Arabic by a professional translator and reviewed for consistency by the investigators. The questionnaire includes socio-demographic characteristics of the participants followed by items related to socio-economic status, pregnancy history, knowledge of contraception, attitude towards contraception and current use of contraception. Also, the questionnaire includes some items to determine the causes for use and reasons for avoiding contraception.

The questionnaire was pre-tested for validity and reliability. It was tested to check if it was easy for the interviewers to understand the instructions and flow of questions. Prior to pre-testing in the field, the interviewers were undergoing training and were provided with instructions about the survey.

\section{Data analysis}

The Student t-test was used to ascertain the significance of differences between mean values of two continuous variables. Chi squared analysis was performed to test for differences in proportions of categorical variables between 2 or more groups. $P<0.05$ considered as the cutoff value for statistical significance. Logistic regression analyses to determine the impact of the main sociodemographic and lifestyle factors of birth control methods. The SPSS Version 22.0 (SPSS Inc., Chicago, IL) and Epilnfo TM Version 7 (Centers for Disease Control and Prevention, Atlanta, GA, USA) were used for statistical analyses.

\section{Results}

A total of 300 Saudi women were approached and 287 consented to participate in this study, giving a response rate of $95.7 \%$. Of these, 13 women were excluded, either due to incomplete questionnaires or they excused themselves before completing the questionnaire due to lack of time.

\section{Sociodemographic and lifestyle characteristics}

The sociodemographicand lifestyle characteristics of the 287 participants in the survey are shown in Table 1. Of these participants, 3.83\%were under 20 years old, $36.24 \%$ were aged between20to 29 , $38.68 \%$ were aged between 30 to 39 and21.25\% aged 40 or over. More than $95 \%$ of the participants lived in urban areas. Education was also associated with attitude to contraception, (76.31\%) had some college or university education and (11.15\%) had completed a degree. Only $41.11 \%$ of the participants were unemployed. Nearly $87 \%$ of the participants were married and living with husband. Only $1.05 \%$ of the participants were smoking cigarettes. Over (65\%) have more than three children. Thirteen percent of qualified participants had experienced an unintended pregnancy (data not shown). 
Table 1. Sociodemographic and lifestyle characteristics of participants (\%) $(n=287)$.

\begin{tabular}{|l|c|c|}
\multicolumn{1}{|c|}{ Characteristics } & No. & $\%$ \\
\hline Age, years & & \\
\hline$<20$ & 11 & 3.83 \\
\hline $20-29$ & 104 & 36.24 \\
\hline $30-39$ & 111 & 38.68 \\
$\geq 40$ & 61 & 21.25 \\
\hline Residence & & \\
\hline Urban & 274 & 95.47 \\
\hline Rural & 13 & 4.53 \\
\hline Marital status & & \\
\hline Married /living with husband & 252 & 87.80 \\
\hline Separated & 35 & 12.20 \\
\hline Education & & \\
\hline No education & 1 & 0.35 \\
\hline High school education or less & 35 & 12.20 \\
\hline College/university & 219 & 76.31 \\
\hline Complete college/university & 32 & 11.15 \\
\hline Smoke cigarettes & & \\
\hline Yes & 3 & 1.05 \\
\hline No & 284 & 98.95 \\
\hline Number of children & & \\
\hline 0 & 12 & 4.18 \\
\hline 1 & 29 & 10.10 \\
\hline 2 & 57 & 19.86 \\
\hline$\geq 3$ & & 65.85 \\
\hline
\end{tabular}

\section{Knowledge about the birth control methods}

Table 2 shows that about 20\% of participants did not read about birth control methods before using them and $18 \%$ of participants did not have any idea about birth control methods side effects. Most of the participants read about oral contraceptive (pills) before using it (39.01\%), followed by women who use intrauterine devices (13.6\%), then participants who use condoms (13.2\%) and transdermal patch (3.8\%). Most of the participants have an idea about oral contraceptive effects before using it (38.6\%), then participants who use condoms (15.1\%), followed by women who use intrauterine devices (13.6\%), and transdermal patch (0.7\%).

\section{Choice of contraceptive method}

Of 287 participants, 40 (13.9\%) never used contraception. Among the 247 women who used contraception, the most frequently used current methods were oral contraceptives (49.1\%), condoms (17.1\%), and intrauterine device (16\%) (Table 3). The transdermal patch, male sterilization and female sterilization were used by $4.5 \%, 0.3 \%$ and $0 \%$ of the participants respectively. Oral contraceptives were the method most commonly used by women who "always" used contraception (86.1\%). Choice of contraceptive method varied by age. The predomi-

Table 2. Knowledge of birth control methods among Saudi women (\%) $(n=247)$.

\begin{tabular}{|c|c|c|c|c|c|c|c|c|}
\hline \multirow[b]{2}{*}{ Variables } & \multicolumn{7}{|c|}{ Contraceptive method } & \multirow{2}{*}{$\begin{array}{c}\text { Total } \\
\text { (\%) }\end{array}$} \\
\hline & Pills & Patch & IUD & Condom & $\begin{array}{c}\text { Female } \\
\text { sterilization }\end{array}$ & $\begin{array}{c}\text { Male } \\
\text { sterilization }\end{array}$ & Others & \\
\hline \multicolumn{9}{|c|}{ Do you read about birth control methods before using them } \\
\hline Yes & 39.01 & 3.8 & 13.6 & 13.2 & 0 & 0.35 & 9.4 & 79.4 \\
\hline No & 10.1 & 0.7 & 2.4 & 3.8 & 0 & 0 & 3.5 & 20.5 \\
\hline \multicolumn{9}{|l|}{ Total\% } \\
\hline & 49.11 & 4.5 & 16 & 17 & 0 & 0.35 & 12.9 & 100 \\
\hline \multicolumn{9}{|c|}{ Do you have an idea about birth control methods side effects } \\
\hline Yes & 38.6 & 3.8 & 13.6 & 15.1 & 0 & 0.35 & 10.5 & 81.9 \\
\hline No & 10.5 & 0.7 & 2.4 & 2.1 & 0 & 0 & 2.4 & 18.1 \\
\hline \multicolumn{9}{|l|}{ Total\% } \\
\hline & 49.1 & 4.5 & 16 & 17.2 & 0 & 0.35 & 12.9 & 100 \\
\hline
\end{tabular}


Table 3. Methods of contraception currently used by Saudi women, by age $(\%)(n=247)$.

\begin{tabular}{|l|c|c|c|c|c|}
\hline $\begin{array}{l}\text { Contraceptive } \\
\text { method }\end{array}$ & \multicolumn{4}{|c|}{ Age (years) } & Total \\
\hline Oral & $20-29$ & $30-39$ & $\geq 40$ & $\%$ \\
\hline contraceptive & 2.1 & 19.5 & 19.2 & 8.4 & 49.1 \\
\hline Patch & 0.3 & 1.4 & 2.1 & 0.7 & 4.5 \\
\hline IUD & 0.7 & 2.4 & 6.3 & 6.6 & 16 \\
\hline Condom & 0.7 & 8.4 & 4.9 & 3.1 & 17.1 \\
\hline $\begin{array}{l}\text { Female } \\
\text { sterilization }\end{array}$ & 0 & 0 & 0 & 0 & 0 \\
\hline Male sterilization & 0 & 0 & 0.3 & 0 & 0.3 \\
\hline Others & 0 & 4.5 & 5.9 & 2.4 & 12.9 \\
\hline Total (\%) & 3.8 & 36.2 & 38.7 & 21.3 & 100.0 \\
\hline
\end{tabular}

nant methods in the women under 20 age group were oral contraceptive $(2.1 \%)$, condom $(0.7 \%)$, intrauterine device $(0.7 \%)$, and transdermal patch $(0.3 \%)$. In the over 40 age group, the predominant contraceptive methods were oral contraceptive $(8.4 \%)$, intrauterine device $(6.6 \%)$, condom $(3.1 \%)$, and transdermal patch (0.7\%).Also, choice of contraceptive method depends on the medical conditions that present before uses of birth control methods.

Chest pain was the most common medical conditions that women had (5.67\%), followed by high blood pressure (4.50\%), gallbladder problems (4.04\%), and diabetes (3.23\%) (Table 4).

\section{Attitudes towards fertility and contraceptives}

Table 5 shows the attitudes of the participants towards fertility as indicated by the number of children. Most of the participants preferred to have three children or more (65.9\%), and (19.9\%) preferred to have two children. Only, $10.1 \%$ of women desired to have one child, and $4.2 \%$ of women desired no children. Non use of contraceptives was explained by several reasons: The first reason, women try to be pregnant (36.93\%), during lactation period $(24.74 \%)$. Some women did not use con- traceptive methods without any reasons (22.65\%) or because using of contraceptive method make them feel bad (18.47\%).

However, few women who did not use contraceptives because they considered it to be against their religious beliefs (8.36\%) (figure 1).

Table 4. Medical conditions that participants had (\%) $(n=247)$.

\begin{tabular}{|l|c|c|}
\hline \multicolumn{1}{|c|}{ Medical conditions } & No. & \% \\
\hline Heart disease & 6 & 2.43 \\
\hline Blood clots & 4 & 1.60 \\
\hline High blood pressure & 11 & 4.50 \\
\hline Gallbladder problems & 10 & 4.04 \\
\hline Diabetes Mellitus & 8 & 3.23 \\
\hline Chest pain & 14 & 5.67 \\
\hline Liver problems & 3 & 1.21 \\
\hline No disease & 191 & 77.33 \\
\hline Total (\%) & 247 & 100 \\
\hline
\end{tabular}

Table 5. Participants' attitudes and use of contraceptives (\%) ( $n=287)$.

\begin{tabular}{|l|c|c|}
\hline \multicolumn{1}{|c|}{ Characteristics } & No. & $\%$ \\
\hline Desired number of children & & \\
\hline 0 & 12 & 4.18 \\
\hline 1 & 29 & 10.10 \\
\hline 2 & 57 & 19.86 \\
\hline$\geq 3$ & 189 & 65.85 \\
\hline Use of contraceptives & & \\
\hline Non-user & 40 & 2.43 \\
\hline User & 247 & 1.60 \\
\hline Use of contraceptives & & \\
\hline Pills & 141 & 49.1 \\
\hline Patch & 13 & 4.5 \\
\hline IUD & 46 & 16 \\
\hline Condom & 49 & 17.1 \\
\hline Female sterilization & 0 & 0 \\
\hline Male sterilization & 1 & 0.3 \\
\hline
\end{tabular}


Figure 1: Attitudes towards fertility and contraceptives.

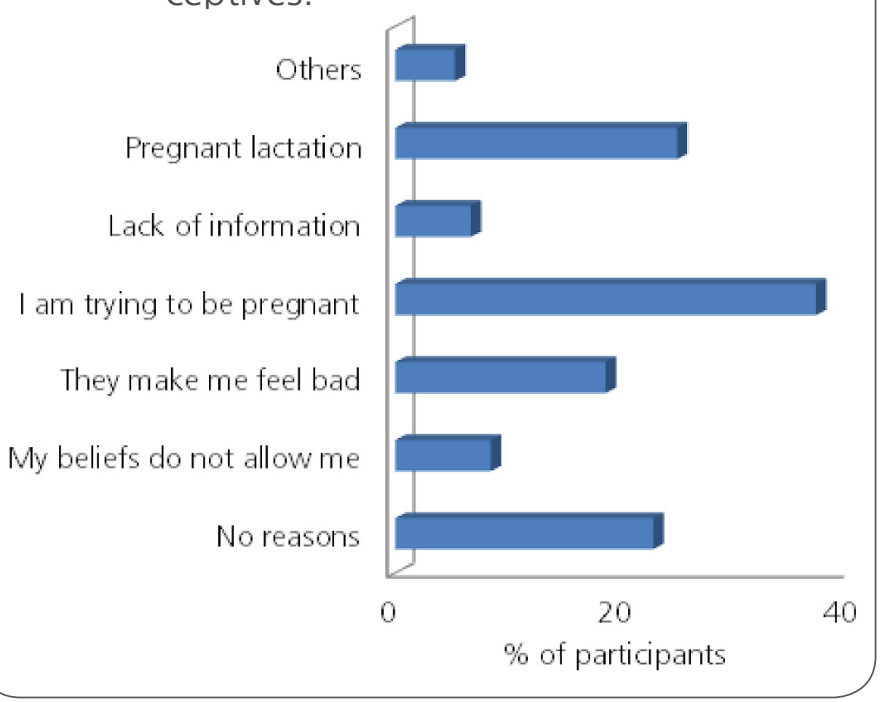

Table 6. Attitude of studied sample towards contraception.

\begin{tabular}{|l|c|c|}
\hline \multicolumn{1}{c|}{ Attitude } & Frequency & Percent \\
\hline Negative & 40 & 13.9 \\
\hline Neutral & 187 & 65.16 \\
\hline Positive & 60 & 20.9 \\
\hline Total & 287 & 100.0 \\
\hline
\end{tabular}

\section{Attitude towards contraception}

Table 6 demonstrates attitude of the studied sample towards contraception. About one fifth (20.9\%) of them had a positive attitude.

\section{Usage of contraceptive methods, sociodemographic and lifestyle characteristics}

Table 7 shows that women used birth control methods and belonging to age groups 20-29 and $30-39$ were significantly more (28.6 and $34.8 \%$, respectively) compared to the younger and older age groups (2.8 and 19.9\%, respectively).Women lived in urban areas (82.2\%) are much used birth control methods than those lived in rural areas. Birth control methods use by women living with the husband was significantly more (78\%) compared to the married separated women (8\%) (OR=0.51; $\mathrm{P}<0.000)$. Utilization of contraception also increased significantly with the increasing level of education (complete college, 64.8\%). Women who complete college used birth control methods more than the other levels of education. On comparing the women who were at work and those who were not working, the working

Table 7. Distribution of female victims of rape as a category of gestational age and sociodemographic characteristics, São Paulo, 1994-2013.

Sociodemographic and lifestyle characteristics

\begin{tabular}{|c|c|c|c|}
\hline \multicolumn{3}{|c|}{ Used of birth control methods before } \\
\hline \multicolumn{3}{|c|}{ No } \\
\hline$\%$ & No. & Yes & No. \\
\hline
\end{tabular}

Age, years

$<20$

$20-29$

30-39

$\geq 40$

Residence

Urban

Rural

Marital status

Married/living with husband

Separated

Education

No education

High school education

College/university

Complete college /university

$$
2.8
$$

28.6

34.8

19.9

57

236

11

82.2

3.8

224

78.0

8.0

23

\section{1}

30

186

30
0.3

10.5

64.8

10.5

3

22

11

4

38

2

13.2

0.7

9.8

4.2

12

12

\section{0}

0

1.7

11.5

0.7 $\times 2$

(P value)

OR

1\#

10.42

$(0.015)^{\star}$

$0.71(0.18-2.92)$

$0.41(0.188-0.895)$

$0.64(0.194-2.1)$

$1 \#$

$1.13(0.241-5.294)$

0.024

$(0.877)$

13.76

$(0.000)^{*}$

1\#

$0.51(0.116-2.264)$ 


\begin{tabular}{|c|c|c|c|c|c|c|}
\hline \multirow{3}{*}{$\begin{array}{l}\text { Sociodemographic and } \\
\text { lifestyle characteristics }\end{array}$} & \multicolumn{4}{|c|}{ Used of birth control methods before } & \multirow{3}{*}{$\begin{array}{c}\times 2 \\
\text { (P value) }\end{array}$} & \multirow{3}{*}{ OR } \\
\hline & \multicolumn{2}{|c|}{ No } & \multicolumn{2}{|c|}{ Yes } & & \\
\hline & $\%$ & No. & $\%$ & No. & & \\
\hline \multicolumn{7}{|l|}{ Work } \\
\hline Working & 149 & 51.9 & 20 & 7.0 & \multirow{2}{*}{$\begin{array}{c}1.515 \\
(0.218)\end{array}$} & 1\# \\
\hline Not working & 98 & 34.1 & 20 & 7.0 & & 1.52(0.777-2.972) \\
\hline \multicolumn{7}{|l|}{ Smoke cigarettes } \\
\hline Yes & 1 & 0.3 & 2 & 0.7 & \multirow{2}{*}{$\begin{array}{c}7.027 \\
(0.008)^{*}\end{array}$} & 1\# \\
\hline No & 247 & 85.7 & 38 & 13.2 & & $0.08(0.007-0.872)$ \\
\hline \multicolumn{7}{|l|}{ Number of children } \\
\hline 0 & 9 & 3.1 & 3 & 1.0 & \multirow{4}{*}{$\begin{array}{c}2.82 \\
(0.420)\end{array}$} & $1 \#$ \\
\hline 1 & 23 & 8.0 & 6 & 2.1 & & $0.78(0.16-3.821)$ \\
\hline 2 & 49 & 17.1 & 8 & 2.8 & & $0.63(0.195-2.01)$ \\
\hline$\geq 3$ & 166 & 57.8 & 23 & 8.0 & & $0.85(0.357-2.02)$ \\
\hline \multicolumn{6}{|c|}{ \# Reference group } & * Significan \\
\hline
\end{tabular}

women showed significantly more use of birth control methods compared to non- working women. On comparing the women who not smoking and those who were smoking, the not smoking women showed significantly more use of contraceptives $(85.7 \%)$ compared to smoking women (0.3\%) $(\mathrm{OR}=0.08 ; \mathrm{P}<0.008)$. Women with higher parity (3 and more) were using birth control methods more than twice as much as those with 1-2 children. Table 7 showed the results of multivariate logistic regression analyses of all studied socioeconomic variables. It showed that there no variable was significantly associated with the birth control method.

\section{Side effects of contraceptive methods}

Of the participants, 247 were used contraceptive methods reportedone or more side effects of the method. The most common complications identified by women were headache (27.12\%), emotional change (27.12\%), depression (16.5\%), and nausea $(11.33 \%)$ regardless the method of contraceptive use (Table 8).

Side effects of contraceptive pills, intrauterine device and contraceptive patches

Figure 2 shows that headache was the most common side effect of oral contraceptive pills (100\%),
Table 8. Side effects of contraceptive use (\%) ( $n=247)$.

\begin{tabular}{|l|c|c|}
\hline \multicolumn{1}{|c|}{ Side effect } & No. & $\%$ \\
\hline Headache & 67 & 27.12 \\
\hline Nausea & 28 & 11.33 \\
\hline Lump of the breast & 10 & 4.04 \\
\hline Depression & 41 & 16.5 \\
\hline Emotional change & 67 & 27.12 \\
\hline Stomach complaint & 17 & 6.8 \\
\hline Heavy vaginal bleeding between period & 10 & 4.04 \\
\hline Other side effects & 7 & 3.83 \\
\hline Total & 247 & 100.0 \\
\hline
\end{tabular}

Figure 2: Side effects of contraceptives pills.

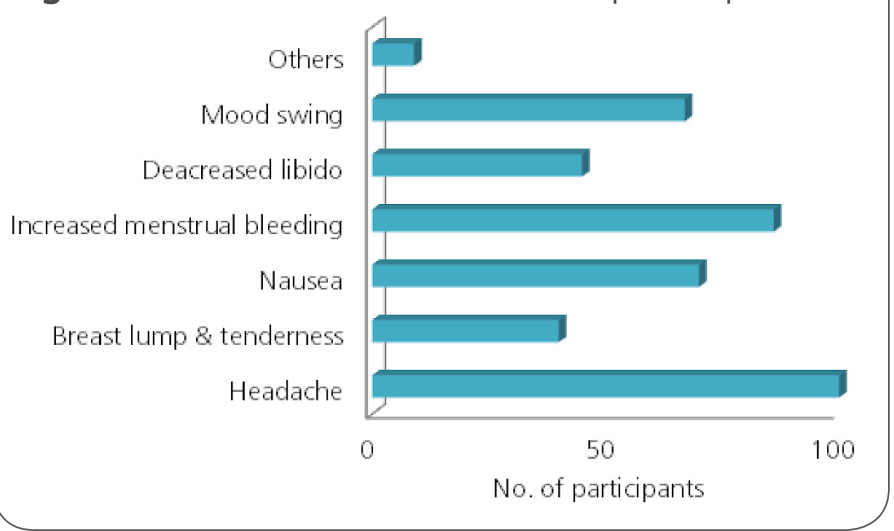


followed by increase menstrual bleeding (87\%), nausea (70\%), and mood swing (67\%).On the other hand, figure 3 shows that abdominal pain was the most common side effect of intrauterine device $(30 \%)$, increase menstrual bleeding (27\%), then other side effects (3\%).While, figure 4 shows that headache was the most common side effect of transdermal patch (10\%), followed by menstrual bleeding (8\%), breast lump and tenderness (5\%), and nausea (4\%).

Figure 3: Side effects of intrauterine device.

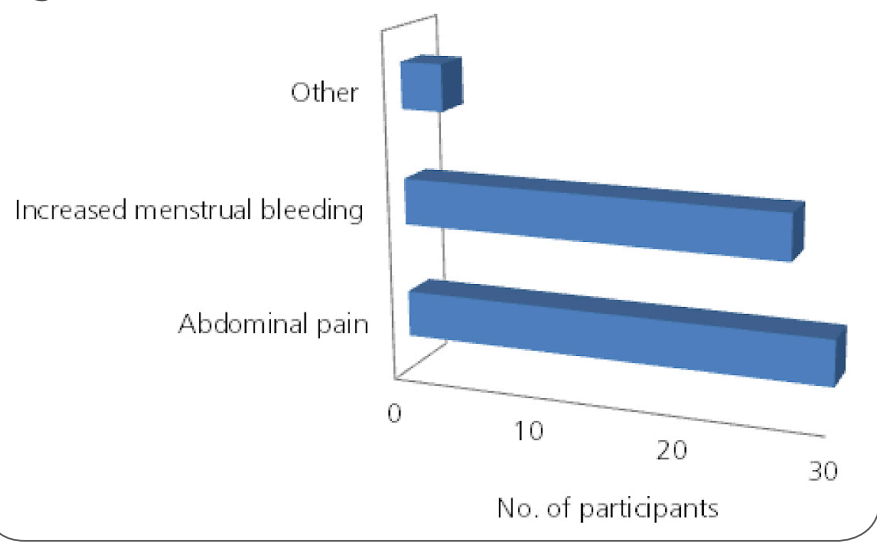

Figure 4: Side effects of contraceptive patches.

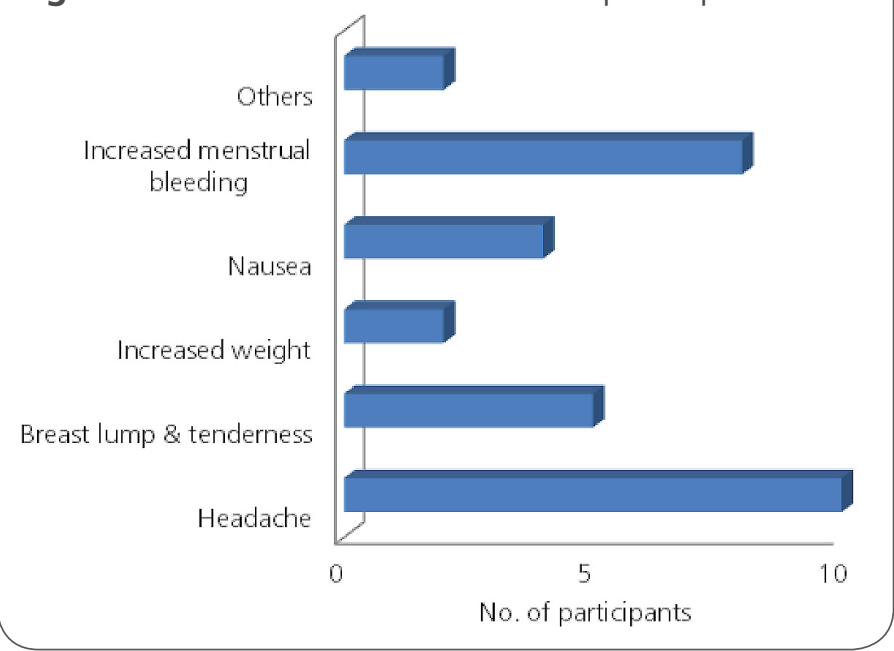

Time interval between stopping the common birth control methods and getting pregnant again

On analyzing data which present in table $\mathbf{9}$, according to type of contraception, it was found that the longest mean time was for oral contraceptive (8.3 months) followed by IUD (5.4 months) and the least for condom (1.5 months).

Table 9. Time interval between stopping the Common Birth control methods and getting pregnant again

\begin{tabular}{|c|c|c|c|c|}
\hline \multirow{2}{*}{$\begin{array}{l}\text { Common Birth } \\
\text { control methods }\end{array}$} & \multirow{2}{*}{ No. } & Mean \pm SD & \multicolumn{2}{|c|}{ ANOVA } \\
\hline & & (Month) & $\mathbf{F}$ & $\mathbf{P}$ \\
\hline Oral contraceptive & 140 & $8.25 \pm 1.985$ & \multirow{3}{*}{321.33} & \multirow{3}{*}{0.000} \\
\hline IUD & 46 & $5.35 \pm 1.041$ & & \\
\hline Condom & 49 & $1.54 \pm 0.489$ & & \\
\hline
\end{tabular}

\section{Discussion}

Contraception is an important aspect of reproductive health care for women and health care providers. Contraceptive choices are important in that they not only provide birth control but may also affect the sexual desire and function, have different side-effect profiles, and provide non-contraceptive benefits [16].

The use of contraception can have an impact on better child spacing, better child care, improvement of children's health, and is regarded as an important preventive measure against maternal and child morbidity. [17]

There was a strong association between the participant's age and the use of contraceptive methods. This could be satisfied with the number of children she has had and feels that she needs more spacing for preserving her health.

The present study illustrated that use of contraceptive methods, increasing with increasing age. In agreement with our results Farheen [7] found that the use of contraceptives increases with the increasing age of the mother. Maximum use is found in females between 30-39 years age group, which is $46.39 \%$ of the total users. In a study conducted among Jordanian women in 2001 revealed that the percentage of use was increasing with increasing age in women aged less than $\mathbf{4 0}$ years. [15] 
Good knowledge of contraceptive methods among Saudi women was shown in the present study, since $86.06 \%$ of women used contraceptive methods. Al-Sheeha [2] showed that $27.1 \%$ of women in Al-Qassim Region, Saudi Arabia had excellent and good knowledge regarding contraception. Also a study in India mentioned that $11.2 \%$ of the study-population was aware of contraception. [18] Other studies in Pakistan and in rural southern $\mathrm{Ni}-$ geria revealed a higher value of awareness of contraception (81\% and 92.2\%, respectively). [19]

There are wide variations in the reported use of contraceptives in Saudi Arabia. Alsheeha [2] conducted a research in 2010 in the Qassim region revealed that $(44.8 \%)$ were using or had used a contraceptive method. In another study in Abha, those who used contraceptives represented approximately (23.8\%) of women. [7]

This study showed that the preferable type of contraception was oral contraceptive (49.1\%), then condom (17.1\%), and intrauterine device (16\%).A study in Saudi Arabia, which showed that (78.3\%) of women preferred pills and (20.2\%) used an intrauterine device. [20] A study in Abha in 2013 showed that $62.9 \%$ of women used pills and $37.1 \%$ used Intra Uterine Device (IUD). [7] Another study in Canada in 2009 showed that (54.3\%) of women preferred condom and (43.7\%) used pills [16]. In developing countries, four modern contraceptive methods, oral contraceptives, IUDs, injectables, and female sterilization are the most widely used methods among married women. [21] However, the recent United Nation's report (2007) about contraceptive use worldwide showed more use of condoms among the Saudi population and to be the second most common used method after pills, which matches the trend of developed countries. [22]

Use of different types of contraception increase among working women, 30 years and older, with a higher level of education, and those having large number of children which is in agreement with the study reported in Saudi Arabia. [2] The study in Abha, showed that women who preferred IUD were mostly working women. As for women with obstetric/medical history preferred pills. The study concluded that different methods of contraception and their benefits for both mother and children must be emphasized. [7]

As regards the use of contraceptive methods, illiterate women were the least likely to practice any contraceptive method and women with university or college education constituted the majority of the sample that were currently using any contraceptive method. The same finding is similar to that done among Qatari women. [23]

The present study also showed that (20.9\%) had positive attitudes compared to (13.9\%) had a negative attitude toward contraception. In general, negative attitudes still prevail across countries and positive attitudes are prevalent in Europe. [24]

More than half of participants in this study preferred to three children or more (65.85\%). Alsheeha [2] found that the majority of women preferred to have at least 5 and up to 10 children, which means that the women would not stop having children throughout her reproductive life. In Nigeria, there was a desire for large families resulting from positive values attached to family life, marriage and procreation. The desire for a large family was deeply rooted in the fundamental belief that children are a gift from God. [25] Arab women tended to avoid the use of contraception unless they had decided they had had a sufficient number of children, particularly at a certain age, and to let God decide on the ideal number of children. In addition, men play a significant role in determining childbearing. [26]

Good knowledge of contraceptive methods among Saudi women was (79.4\%) compared to (20.5\%) with poor knowledge in this study. This is inconsistent with the result reported by Al-Sheeha [2] in 2010 that 27.1\% of women in Al- Qassim Region, Saudi Arabia had excellent and good knowledge regarding contraception. Also a study in India 
mentioned that $11.2 \%$ of the study-population was aware of contraception. [18]

In the present study age, marital status, and smoking were a significant factor associated with attitude toward contraception methods. However, Alsheeha [2] study mentioned that higher education, better knowledge, and those working are a significant factor associated with attitude toward contraception.

This study showed that the most common complications identified by women were headache (37.63\%), emotional change (37.63\%). A survey of United Kingdom healthcare professionals found that $87 \%$ believed that the contraceptive pills cause mood changes [27].

\section{Conclusion}

The results of the present study demonstrated reasonable knowledge and attitude of Saudi women regarding birth control methods. Socio-demographic status and lifestyle are significantly associated with knowledge of contraceptive methods, and attitude toward both contraception and OCP for child spacing. Future public health initiatives in Saudi Arabia should focus on raising awareness of all options for contraception, promoting dual protection, increasing access to a variety of contraceptive methods, and assisting Saudi women in maximizing their contraceptive adherence.

\section{References}

1. Yalew S A, ZelekeB M, Teferra AS. Demand for long acting contraceptive methods and associated factors among family planning service users, Northwest Ethiopia: a health facility based cross sectional study. BMC Res Notes. 2015; 8: 29.

2. Al Sheeha M. Awareness and use of contraceptives among Saudi women attending primary care centers in Al-qassim, Saudi Arabia. Int J Health Sci (Qassim). 2010; 4(1): 11-21.

3. Al Sbiani SA. Use of misoprostol for self-induced medical abortions among Saudi women: a call for attention. Gynecol Obstet Invest. 2014: 78(2): 88-93.

4. Ahmed S. Saudi parent's attitude and practice about selfmedicating their children. Arch Pharm Pract. 2013; 4: 57-62.

5. Suleiman AK. Self-medication and the advisory role of pharmacists in Riyadh, Saudi Arabia. Arch Pharma Pract. 2013; 4(4): 180-5.

6. Al-Mansour R, Sabra AA, Hafez AS. Contraception: knowledge, attitudes and practice with special emphasis on contraceptive pills among Saudi women at Al-Khobar City, Eastern Saudi Arabia. Egyptian Journal of Community Medicine. 2012; 30(2): 1-13.

7. Farheen A. Ever use of contraceptive among women attending primary health care centers at ABHA, Saudi Arabia. Int J Cur Res Rev. 2013; 5(10): 26-32.

8. Al-turki H A. Contraception: attitudes and experiences of Saudi Arabian women. Health Care for Women International. (2011); 32: 134-9.

9. Choe MK, Luther NY, Pandey A, Sahu D, Chand J. Identifying children with high mortality risk. National Family Health Survey Bulletin No. 12. Mumbai: International Institute for Population Sciences; and Honolulu: East-West Center, 1999.

10. Entwistle VA, Sheldon TA, Sowden A, Watt I. Evidence-informed patient choice. Practical issues of involving patients in decisions about health care technologies. International Journal of Health Technology Assessment in Health Care. 1998; 14: 212-25.

11. Hope T. Evidence-based patient choice. London: King's Fund, 1996.

12. Mosher WD, Jones J. Use of contraception in the United States: 1982-2008: National Center for Health Statistics Vital Health State. 2010; 29: 1-44.

13. Kavanaugh ML, Jerman J, Hubacher D, Kost K, Finer, LB. Characteristics of women in the United States who use longacting reversible contraceptive methods. Obstet Gynecol. 2011; 117: 1349-57.

14. Peipert JF, Zhao Q, Allsworth, JE, Petrosky E, Madden T, Eisenberg $D$, et al. Continuation and satisfaction of reversible contraception. Obstet Gynecol 2011; 117: 1105-13.

15. Takkar N, Goel P, Saha PK, Dua D. Contraceptive practices and awareness of emergency contraception in educated working women. Indian J Med Sci. 2005; 59: 143-149. 
16. Black A, Francoeur D, Rowe T, Collins J, Miller D. Contraception Guidelines Committee. Canadian contraception consensus. SOGC Clinical Practice Guideline. J Obstet Gynaecol Can. 2004; 26(3): 219-96

17. Utoo BT, Mutihir TJ, Utoo PM. Knowledge, attitude and practice of family planning methods among women attending antenatal clinic in Jos, North-central Nigeria. Niger J Med. 2010; 19(2): 214-8.

18. Shakhatreh, FM. Contraceptive use in Jordan. Saudi Med J 2001; 22 (6): 512-5.

19. Omo-Aghoja LO, Omo-Aghoja VW, Aghoja CO, Okonofua FE, Aghedo O, Umueri C. Factors associated with the knowledge, practice and perception of contraception in rural southern Nigeria. Ghana Med J. 2009; 43(3): 115-21.

20. Mahboub S, Abdelkader S, Al-Muhanna A, Al-Musallam F, Al -Ghannam J, Al-Munyif S. Attitude towards contraceptives use among Saudi women. International Journal of Healthcare Sciences. 2015; 2(2): 331-9.

21. Kenny L. Contraception, sterilization and termination of pregnancy. In Luesley DM, Baker PN (Ed), Obstetrics and Gynecology. An evidence based text book for MRCOG. Arnold London. 2014; p. 514-23.

22. Arbab AA, Bener A, Abdulmalik M. Prevalence, awareness and determinants of contraceptive use in Qatari women. East Mediterr Health. 2011; 17(1): 11-18.

23. Albezrah NA. Use of modern family planning methods among Saudi women in Taif, KSA. Int J Reprod Contracept Obstet Gynecol. 2015; 4(4): 990-4.

24. Lee J, Jezewski MA. Attitudes toward oral contraceptive use among women of reproductive age: a systematic review. ANS Adv Nurs Sci. 2007; 30(1): E85-103.

25. Duze MC, Mohammed IZ. Male knowledge, attitudes, and family planning practices in northern Nigeria. Afr J Reprod Health. 2006; 10(3): 53-65.

26. Petro-Nustas W. Men's knowledge of and attitudes toward birth spacing and contraceptive use in Jordan. International Family Planning Perspectives. 1999; 25: 181-5.

27. Wellings K, Zhihong Z, Krentel A, Barrett G, Glasier A. Attitudes towards long-acting reversible methods of contraception in general practice in the UK. Contraception. 2007; 76: 208-14.

\section{Comment on this article:}

\section{(f) $[$ in $8+\boldsymbol{S} P$}

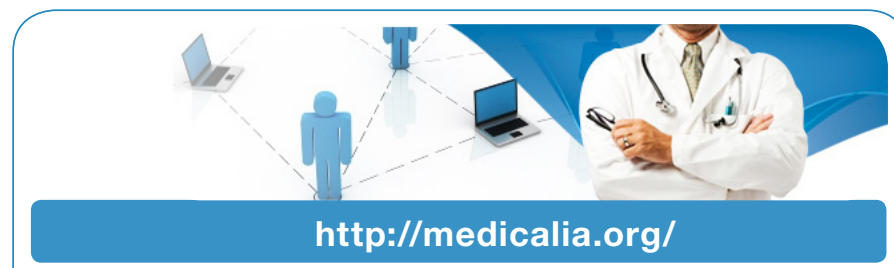

Where Doctors exchange clinical experiences, review their cases and share clinical knowledge. You can also access lots of medical publications for free. Join Now!

\section{Publish with iMedPub}

http://www.imed.pub

International Archives of Medicine is an open access journal publishing articles encompassing all aspects of medical science and clinical practice. IAM is considered a megajournal with independent sections on all areas of medicine. IAM is a really international journal with authors and board members from all around the world. The journal is widely indexed and classified Q1 in category Medicine. 